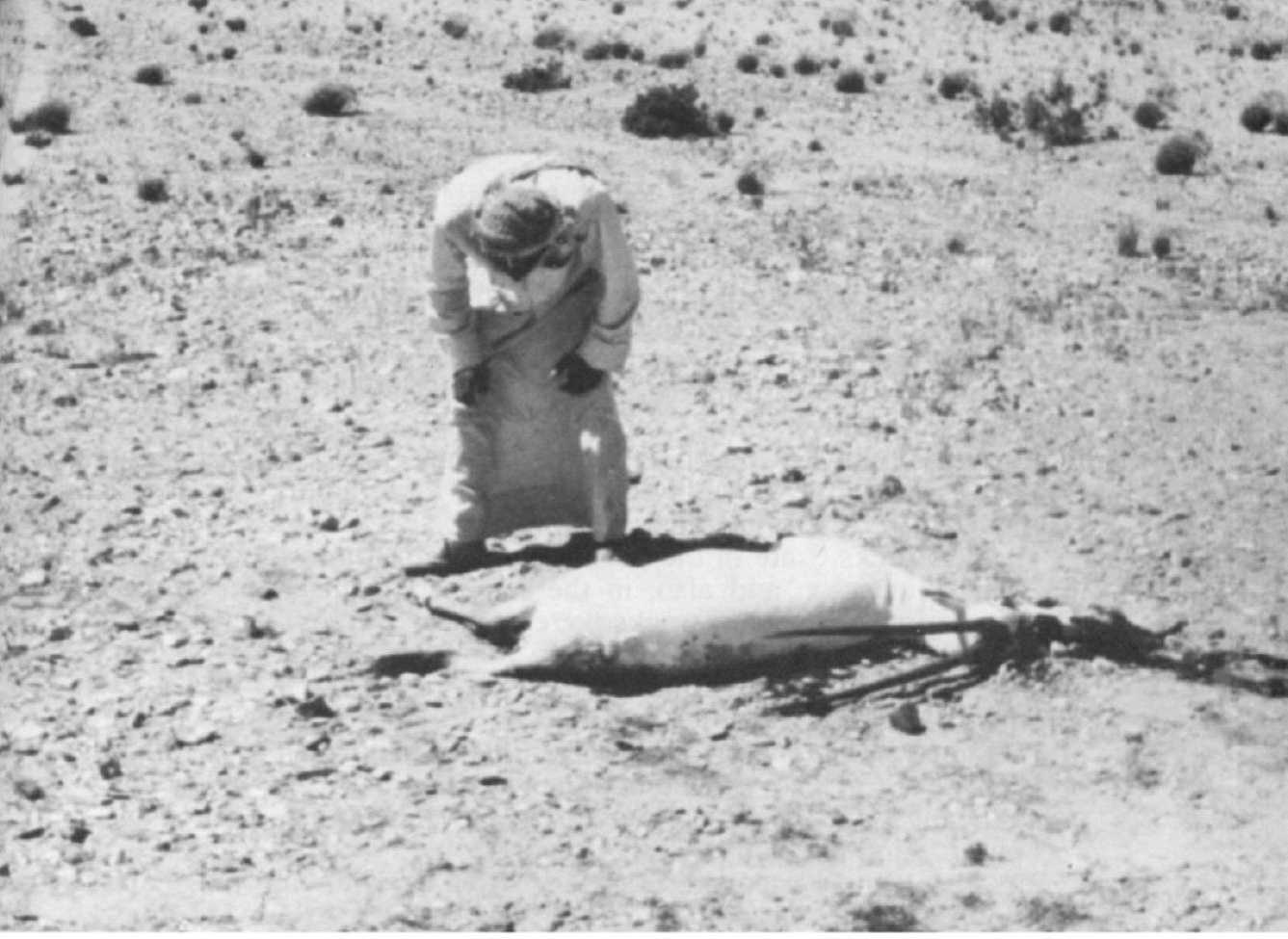

\title{
Were They the Last Arabian Oryx?
}

\section{S. Henderson}

In this account of a safari to look for Arabian oryx in Oman-home of probably the last survivors in the wild - the author found remains of three dead animals and evidence for the chasing and capture alive of four more. These, he believes, were the last wild Arabian oryx. Other observers think that it is too soon to say, and emphasise the vastness of the area, but certainly, in the interval since this safari in October 1972, no reports of wild Arabian oryx have been received by the FPS.

My oryx photographic safari in October 1972 produced irrefutable evidence that a very recent poaching party, at first thought to be from Abu Dhabi but almost certainly from a northern state, had killed and/or removed the last of Oman's, and possibly the world's, wild Arabian oryx. Our expedition found three dead oryx (or their remains) with unquestionable evidence that four had been seized and captured by pursuing vehicles.

At the time of our expedition Sheikh Salim Bin Hunelat, a man for whom I have very real admiration, and who had been keeping a close watch on the oryx's movements immediately prior to the Sultan's fairly recent visit to the area, considered that only three animals remained. But over a period of days we built up evidence that six and possibly seven animals existed. By the end of the 
investigation, however, there was little doubt that they had all been accounted for by the poachers.

I left Mina al Fahal, a few miles north of Muscat, on October 15 th, reaching my starting point in central Oman late the next evening. On the 17th, moving in a WSW-ESE arc, I began the search for the oryx, accompanied by Sheikh Salim bin Hunelat (who said he was not prepared to let me into the area unsupervised) and by an excellent guide, another Harasis, Fahad Yahir, whose Landrover I hired as a second vehicle. That evening we found the first oryx tracks, the $7 / 10$ day-old tracks of three adults and a calf. We camped in their immediate area. The next day we spent looking for fresher tracks. Late in the evening we again found the tracks of the same four oryx, and also, in the same area, the tracks of two running oryx. Both sets of tracks were at least five days old. Earlier in the day we had found a $2 / 3$ day-old vehicle tracks. Sheikh Salim, who was clearly worried at finding them, expressed the fear that they belonged to a Sheikh from Abu Dhabi and that it was possible that already the remaining oryx had been killed. Sheikh Salim and I did not know each other well at this time and, thinking back, I now find it significant that for several hours after finding the vehicle tracks he was pensive and preoccupied.

On the 19th we covered a wide area in our morning and afternoon/evening searches, finding no tracks fresher than 5/7 days. Again we found the tracks of the two lots of oryx, one of four and one of two running animals, an observation that clearly worried Sheikh Salim. We also found freshish ( $2 / 3$ day old?) vehicle tracks, this time of two vehicles. This worried Sheikh Salim so much that he asked if we could use the emergency search and rescue transmitter (for use if we broke down) to alert the authorities. (This was technically not possible).

In view of his mounting worry, Sheikh Salim diverted to nightstop at a Bedouin camp specifically to seek information about recent vehicle movements in the area. Here another Harasis, Mohammed, said a Sheikh from Abu Dhabi--the one named by Sheikh Salimhad moved into the area about eight days previously with the announced intention of capturing, as opposed to killing, all the oryx he could find. My recollection is that Mohammed (a capable, alert and very helpful man) in the first instance said this Sheikh stayed with him for four nights, driving round the area by day. Sometime later Sheikh Salim reduced this period to one night. My orderly, with very limited English, who was the only interpreter, could have made a genuine error but it seems unlikely in view of the area to cover (2500 square miles) that they would have spent so long in the same area.

On October 20th, accompanied by Mohammed, we moved to an area Sheikh Salim considered unlikely to have been visited by the poachers and where, ten days before Mohammed had seen two

Above: Scuff marks and vehicle tracks that revealed the capture of oryx no. 6 Below: The remains of two oryx, one a calf-and clear vehicle tracks. D. S. Henderson 
mature oryx. A search, both in the morning and afternoon/evening produced only tracks $5 / 7$ days old, again of the same two lots of four and two oryx and again with the two oryx running. We also found tracks of two vehicles, this time not more than three days old.

Just before dark, returning to Heima to refuel, etc., we found more fresh vehicle tracks. Then in minutes, literally just before the sun set, we found a dead mature male oryx lying between converging landrover tracks. It had bled heavily from the head and mouth, and appeared to have been hit by (or to have hit) a vehicle. It certainly had not been shot and seemed to have been dead for between 24/48 hours. Sheikh Salim thought that the animal had been chased for upwards of two days, literally to exhaustion, and its lungs had burst. A photograph is on page 347.

About eighty yards back from the dead oryx we found 'scuff' marks and more converging vehicle tracks, indicating that a second oryx had been seized by a pursuing vehicle. I took 'insurance' pictures by flash, before returning to our base-a desert base made available by courtesy of Petroleum Development (Oman) Ltd.

On the 22nd we began a thorough search, first by following landrover tracks away from the dead animal. In two hours, and in an area not larger than 16 square miles, we found the remains of two more oryx: the head, stomach and skin of a mature animal, and the stomach of a young calf. (There were no tracks or scuff marks). We also found clear evidence of the capture from vehicles of three more animals.

To sum up (and to stress the gravity of what had happened) we found three dead oryx (or sufficient remains to establish three deaths) and scuff marks of four successful snatches. We had found evidence of six, maybe seven oryx in the area (the only area where they are found in Oman) and there can be little doubt that at least this number have been accounted for, and with three or four actually captured.

For the next seven days, with an increasing sense of frustration, we searched as much of the area as possible and found no evidence whatever to suggest any oryx had escaped. Admittedly the area is vast and little travelled, but from what we found and evidence collected since, the fear grows that the oryx killed and captured could well have been the last wild Arabian oryx. Even if a handful remain what we found undoubtedly ranks as a major wildlife disaster.

\section{Hawksbills off Madagascar}

Madagascar is famous as a source of tortoiseshell, but persistent exploitation of the vast numbers of hawksbill turtles that used to occur around the island has led to a drastic reduction in their population. Exports of tortoiseshell have fallen from $4000 \mathrm{~kg}$ per annum to a few hundred. George R. Hughes, who has been surveying the turtles of Madagascar, urges that a strong effort be made to stop the killing of nesting hawksbill females, that any killing should only be done under licence, and that very few licences should be issued. 